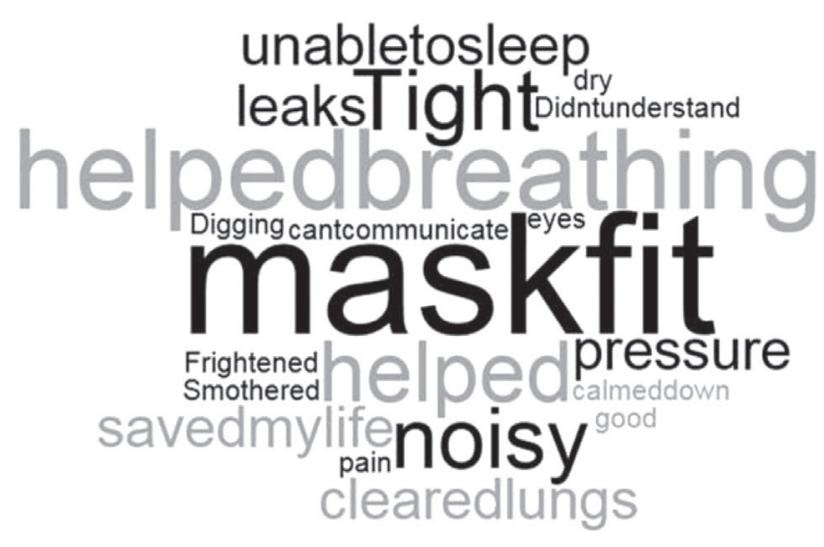

Abstract P75 Figure 1 Word-cloud to represent patient experience of NIV ( $n=15$ patients, 5 relatives). (Size of word is proportional to the frequency of use of word in response to being asked to describe NIV, Black association with negative experience grey with positive).

\section{P76 INITIATION OF LONG-TERM NON-INVASIVE VENTILATION (NIV) IN A SPECIALIST RESPIRATORY FAILURE UNIT IN THE UK}

SJ Tetlow, PS Marino, PD Murphy, H Pattani, J Steier, N Hart. Lane Fox Respiratory Unit, St Thomas' Hospital, London, UK

\subsection{6/thoraxjnl-2016-209333.219}

Introduction and objectives There are currently no guidelines for the provision of long-term NIV and little data into the settings and interfaces employed by different centres. Our aim was to assess long-term NIV provision in a Specialist Respiratory Failure Unit (SRFU).

Methods A retrospective observational study was performed of all patients commenced on long-term NIV by the SRFU. Data was collected from electronic patient records and technician databases on all initiations from August 2014 to January 2015.

Results Data was obtained from 113 patients. Oronasal masks were used in $87 \%$ of patients, nasal pillows in $10 \%$, total face masks in $2 \%$ and nasal masks in $1 \%$. Oronasal masks were used to deliver higher inspiratory positive airway pressures (IPAP) (mean $\pm \mathrm{SD} 23.3 \pm 5.3 \mathrm{~cm} \mathrm{H}_{2} \mathrm{O}$ ). Nasal interface use was associated with lower IPAPs (mean \pm SD $12.5 \pm 4.5$ ). A relatively higher IPAP was applied at initiation to the study group (mean \pm $\mathrm{SD} 22.3 \pm 6.2 \mathrm{~cm} \mathrm{H}_{2} \mathrm{O}$ ) but this varied according to diagnosis; patients with obstructive sleep apnoea (OSA), chronic obstructive pulmonary disease (COPD) and motor neurone disease (MND) received a mean \pm SD IPAP of $24.3 \pm 5.4 \mathrm{~cm} \mathrm{H}_{2} \mathrm{O}, 23.4 \pm 4.2$ $\mathrm{cm}_{2} \mathrm{O}$ and $12.4 \pm 3.6 \mathrm{~cm} \mathrm{H}_{2} \mathrm{O}$ respectively.

Conclusions Oronasal masks were predominantly used reflecting the frequent application of IPAPs above $20 \mathrm{~cm} \mathrm{H}_{2} \mathrm{O}$ as high pressures are poorly tolerated with nasal interfaces. High mean IPAPs were used in OSA and COPD patients, whilst lower IPAPs were administered to MND patients. No guidelines exist for long-term NIV use, with practice on the SRFU differing from the British Thoracic Society's guidelines on acute NIV that recommend a "pressure target" of $20 \mathrm{~cm} \mathrm{H}_{2} \mathrm{O}$ (Royal College Of Physicians et al. Concise Guidance to Good Practice Series, 11). However, the relevance of these guidelines to long-term NIV provision is unclear, and the lack of data has impeded the development of specific guidance. A database of patients receiving long-term NIV in the UK would facilitate research and the formulation of evidence-based best practice guidelines.

\section{P77 EXPERIENCE OF A JOINT PALLIATIVE AND RESPIRATORY CLINIC ON NIV TREATMENT INITIATION IN MOTOR NEURONE DISEASE}

T Burden, C Davis, E Johnstone, J Spence, D Shrikrishna. Musgrave Park Hospital, Taunton, UK

10.1136/thoraxjnl-2016-209333.220

Introduction Signs and symptoms of ventilatory failure are a proxy for disease progression in Motor Neurone Disease (MND). Recent National Institute for Health and Clinical Excellence (NICE) guidance for MND recommends early referral to specialist palliative care (NICE, 2016) and this may help inform patient decisions around the initiation of non-invasive ventilation (NIV)

A service evaluation was conducted on a new joint palliative and respiratory clinic to determine access to specialist palliative care and the initiation of NIV in MND patients.

Methodology The joint palliative care and respiratory clinic began in September 2015, at Musgrove Park hospital, Taunton and all patients with MND were included. Electronic records were retrospectively accessed, both from the acute hospital electronic document system (EPRO) and also the palliative care database (Crosscare). The joint clinic group were compared with patients discussed in the local MND multi-disciplinary team meeting prior to initiation of the joint clinic, who had respiratory symptoms (standard care group).

Results Data was collected in 35 patients with MND. Of these, 9 did not have any respiratory symptoms and were excluded. The joint clinic group $(\mathrm{N}=11)$, included 5 women $(45 \%)$, mean age 67.9 (SD 8.9); in the standard care group $(\mathrm{N}=15)$ there were 7 (47\%) women, mean age 69.2 (7.6) years. Eighty percent of patients receiving standard care were referred to palliative care compared to $100 \%$ in the joint clinic. In the standard care group, $12(80 \%)$ of patients were initiated on NIV compared to $5(45 \%)$ in the joint clinic group. There were only 3 unplanned admissions in both groups and the location of patient deaths were not different.

Conclusion Attending the joint clinic appeared to improve access to palliative care services. Furthermore, patients with MND may benefit from combined palliative and respiratory care input in a joint clinic when making decisions around the initiation of NIV. Further work is needed to evaluate the role of these clinics in informing patient choice for the management of ventilatory failure in this condition.

\section{REFERENCE}

1 National Institute for Health and Care Excellence. Motor Neurone Disease: assessment and management. https://www.nice.org.uk/guidance/ng42?unlid= 3630474112016629201321 (accessed July 2016).

\section{How can we improve lung cancer pathways?}

\section{P78 TACKLING EMERGENCY LUNG CANCER ADMISSIONS}

RV Reddy, Y Vali, M Naeem. Kettering General Hospital, Kettering, UK

10.1136/thoraxjnl-2016-209333.221 
Introduction A significant proportion of lung cancer patients present as an emergency. This is associated with poor one year survival. Many of these patients have had contact with health services before presenting as an emergency. It is estimated that one in five lung cancer patients have an unplanned admission before their urgent clinic appointment. ${ }^{1}$

Objective To reduce the number of emergency lung cancer admissions by providing an effective alternative ambulatory pathway for high risk patients.

Methods Patients referred on the two week wait pathway are vetted by the respiratory physicians. Those identified as having a high risk of admission are prioritised and reviewed urgently on the ambulatory care unit usually by the next working day. Patients with the following features were expedited:

1. Superior vena caval obstruction

2. Liver function abnormalities

3. Large tumour burden on chest radiograph

4. Severe symptoms such as pain and breathlessness

5. Large pleural effusion.

\begin{tabular}{llllll}
\multicolumn{6}{l}{ Abstract P78 Table 1 } \\
\hline \multicolumn{1}{c}{ Year } & $\begin{array}{l}\text { Incidence } \\
\text { of lung } \\
\text { cancer }\end{array}$ & $\begin{array}{l}\text { Total no. of admissions } \\
\text { (\% of lung cancer } \\
\text { incidence) }\end{array}$ & $\begin{array}{l}\text { Length } \\
\text { of } \\
\text { stay }\end{array}$ & $\begin{array}{l}\text { Total } \\
\text { bed- } \\
\text { days }\end{array}$ \\
\hline $\begin{array}{l}\text { Kettering } \\
\text { General }\end{array}$ & $2012-13$ & 195 & $108(55 \%)$ & 11.6 & 1253 \\
$\begin{array}{l}\text { Hospital } \\
\text { England }\end{array}$ & $2012-13$ & 195 & $67(34 \%)$ & 8.1 & 543 \\
$\&$ & $2014-15$ & 33,231 & $18,878(56 \%)$ & 8.9 & 168,014 \\
Wales & & & $17,281(56 \%)$ & 8.9 & 153,800 \\
\hline
\end{tabular}

Patients with suspected lung cancer presenting to the emergency department were also re-directed to the ambulatory care unit whenever feasible. We evaluated the service for a period of 12 months from October 2014 and compared it with the 12 month period prior to the commissioning of the ambulatory care unit in June 2013. As part of the service, the team developed an innovative lung cancer diagnostic service utilising ultrasound guidance to facilitate early diagnosis.

Results Table 1 demonstrates the resulting drop in unplanned lung cancer admissions and length of stay. We estimate a cost saving of $£ 170,000$ based on a 710 bed-day reduction ( $£ 300 /$ bed day) after taking into consideration physician time. If rolled out nationally, reducing the admission rate to $34 \%$ of the lung cancer incidence will avoid 6800 admissions (>55,000 bed-days) with significant cost savings and benefits to patients.

Conclusion Flexible pathways are cost effective and prevent emergency admission of lung cancer patients which is associated with high mortality. This novel approach is easily adoptable widely and would have a significant impact across NHS.

\section{REFERENCE}

1 Tackling emergency presentation of lung cancer: an expert working group report and recommendations. British Lung Foundation, 2015.

\section{P79 SINGLE POINT OF ACCESS CLINIC (SPOAC): A NEW REGIONAL LUNG CANCER PATHWAY IN NEW ZEALAND}

${ }^{1} \mathrm{P}$ Dawkins, ${ }^{2} \mathrm{~J}$ McWilliams, ${ }^{3} \mathrm{R}$ Sullivan. 'Middlemore Hospital, Auckland, New Zealand; ${ }^{2}$ Northern Regional Alliance, Auckland, New Zealand; ${ }^{3}$ Auckland City Hospital, Auckland, New Zealand

\subsection{6/thoraxjnl-2016-209333.222}

Aim A new pathway to enable quicker lung cancer diagnosis for the 4 district health boards within one of the cancer networks in New Zealand was developed incorporating rapid access clinics (RACs), with upfront PET-CT scans for those considered potentially curable at initial assessment.

Methods In this 12-week pilot, patients graded as high suspicion of lung cancer were seen in RACs with spirometry, performance status assessment and available radiology (chest X-ray or CT scan). Those considered potentially curable by surgery or radiotherapy (FEV1 $\geq 1$ litre, ECOG score $<2$, no evidence of mediastinal lymphadenopathy or metastasis on imaging, no comorbidities precluding radical treatment) received an upfront PET-CT scan; those who were not received a standard CT scan if not already done. These protocols were based on the virtual model proposed by the Gleeson group, Oxford, UK. ${ }^{1}$ Time through the pathway was measured and compared with historical data from the regional lung cancer database in a 6 month period the year before the pilot.

Results One hundred and sixty five patients completed the pathway, of which 105 were found to have lung cancer. Forty one patients had upfront PET-CT scans; 30 were confirmed as lung cancer, 7 of which subsequently had palliative treatment. Eleven had non-lung cancer diagnoses (9 not cancer or nodule follow up; 1 metastasis; 1 other cancer). Seventeen patients had PET-CT scans later in the pathway, 4 of which subsequently had curative treatment. Median time from referral to first treatment was reduced by 16.7 days (patients with curative treatment intent 17.2 days and palliative treatment intent 12.7 days), significantly reducing both the time from referral to multidisciplinary meeting (MDM) and MDM to first treatment. Achievement of 62-day target referral to treatment targets was $85.7 \%$ compared with $56.6 \%$ in the historical data.

Conclusion A regional lung cancer pathway incorporating RACs and upfront PET-CT scans for curative track patients resulted in improvements in diagnostic delays and 62-day treatment targets. These findings subsequently led to implementation of this pathway regionally.

The study was funded by a New Zealand Ministry of Health project grant

\section{REFERENCE}

1 Macpherson $R$, et al. A proposed new imaging pathway for patients with suspected lung cancer. Clin Radiol 2012;67(6):564-73.

\section{P80 SYMPTOMS, DELAY TO PRESENTATION AND SURVIVAL IN LUNG CANCER}

${ }^{1}$ WY Chan, ${ }^{2} \mathrm{~A}$ Clark, ${ }^{3} \mathrm{U}$ Dernedde, ${ }^{1} \mathrm{~T}$ Roques, ${ }^{3} \mathrm{M}$ Burton, ${ }^{1} \mathrm{~J}$ Kotecha, ${ }^{2} \mathrm{~A}$ Wilson, ${ }^{1} \mathrm{C}$ Martin. ${ }^{1}$ Norfolk and Nonwich University Hospital, Norwich, UK; ${ }^{2}$ University of East Anglia, Norwich, UK; ${ }^{3}$ James Paget University Hospital, Norwich, UK

10.1136/thoraxjnl-2016-209333.223 